\title{
Compromised concentrations of ascorbate in fluid lining the respiratory tract in human subjects after exposure to ozone
}

Ian S Mudway, Mamidipudi T Krishna, Anthony J Frew, Dominic MacLeod, Thomas Sandstrom, Stephen T Holgate, Frank J Kelly

\begin{abstract}
Objectives-Ozone $\left(\mathrm{O}_{3}\right)$ imposes an oxidative burden on the lung in two ways. Firstly, directly as a consequence of its oxidising character during exposure, and secondly, indirectly by engendering inflammation. In this study the second pathway was considered by ascertaining the impact of $\mathrm{O}_{3}$ on the redox state of the fluid lining the respiratory tract 6 hours after challenge.

Methods-Nine subjects were exposed in a double blind crossover control trial to air and $200 \mathrm{ppb} \mathrm{O}_{3}$ for 2 hours with an intermittent exercise and rest protocol. Blood samples were obtained and lung function (forced vital capacity (FVC), forced expiratory volume in 1 second $\left(F E V_{1}\right)$ ) assessed before, immediately after, and 6 hours after exposure. Bronchoalveolar lavage (BAL) was performed 6 hours after challenge. Inflammation was assessed in BAL fluid (total and differential cell counts, plus myeloperoxidase concentrations), and plasma and BAL fluid redox state were determined by measuring concentrations of antioxidants and markers of oxidative damage.
\end{abstract}

Results-Neutrophil numbers in BAL fluid increased 2.2-fold $(p=0.07) 6$ hours after exposure and this was accompanied by increased myeloperoxidase concentrations in BAL fluid $(p=0.08)$. On the other hand, BAL fluid macrophage and lymphocyte numbers decreased 2.5-fold $(p=0.08)$ and 3.1 -fold $(p=0.08)$, respectively at this time. Of the antioxidants examined, only ascorbate in BAL fluid was affected by $\mathrm{O}_{3}$, falling in all subjects relative to air values $(0.1(0.0-0.3) v 0.3$ $(0.2-1.2) \mu \mathrm{mol} / 1 \quad(p=0.008))$. A marginal decrease in plasma ascorbate was also detected at this time $(p<0.05)$. Although the decrease in macrophage numbers seemed to be causally related to the increase in neutrophils $(R=-0.79)$, myeloperoxidase concentrations $(R=-0.93)$ and ascorbate concentrations $(R=0.66)$, no clear associations were apparent between ascorbate changes and neutrophils or myeloperoxidase concentration after $\mathrm{O}_{3}$. Conclusions-Ascorbate in the fluid lining the respiratory tract is depleted as a consequence of $\mathrm{O}_{3}$ exposure at 6 hours after exposure. This was contemporane- ous with, although not quantitatively related to the increase in neutrophil numbers and myeloperoxidase concentrations. Decreased macrophage numbers 6 hours after $\mathrm{O}_{3}$ related to the degree of neutrophilic inflammation with populations conserved where ascorbate concentration in the fluid lining the respiratory tract were high after exposure. These results imply that ascorbate has a critical protective role against inflammatory oxidative stress induced by $\mathrm{O}_{3}$.

(Occup Environ Med 1999;56:473-481)

Keywords: ozone; antioxidant; ascorbate; bronchoalveolar lavage

Ozone $\left(\mathrm{O}_{3}\right)$ is a highly reactive gas commonly encountered as a component of photochemical smog. It is known to elicit a range of pathophysiological responses in humans at concentrations only 2-3 fold greater than ambient concentrations ${ }^{1}$; concentrations often encountered during episodes of air pollution. ${ }^{2}$ The mechanisms by which symptomatic responses to $\mathrm{O}_{3}$ are manifest are largely unknown, but they are thought to occur as a consequence of the oxidant properties of $\mathrm{O}_{3}{ }^{3}$ which is highly reactive towards a wide range of biomolecules. ${ }^{4}$ This property, allied to its low aqueous solubility, ${ }^{5}$ has led to the belief that $\mathrm{O}_{3}$ toxicity must be interpreted in the context of its initial interactions with components of the fluid lining the respiratory tract (RTLF), ${ }^{6-8}$ the first physical interface encountered by the inspired gas. In this context, reactions with lipid and protein moieties are thought to be potentially injurious, generating toxic mediators, while reactions with aqueous antioxidants such as ascorbate, urate, and reduced glutathione are protective, limiting the extent of the injurious reactions. ${ }^{6}$

Exposure to $\mathrm{O}_{3}$ is also a potent stimulus for airway inflammation. This response, characterised by airway neutrophilia, ${ }^{9}$ represents a secondary source of oxidative stress within the lung. After exposure to $\mathrm{O}_{3}$, two discrete phases of oxidative stress can therefore be envisaged. The first is due to the direct oxidising effects of $\mathrm{O}_{3}$; the second arises from recruitment of inflammatory cells induced by $\mathrm{O}_{3}$, which can release reactive oxygen species ${ }^{10}$ when stimulated. In both cases RTLF antioxidants act to limit injury, although their relative contribution will differ depending on the nature of the specific oxidative insult - that is, $\mathrm{O}_{3}$ or reactive 
oxygen species derived from inflammatory cells. Previously we have shown that urate is consumed in human nasal fluid lining the respiratory tract during exposure to $200 \mathrm{ppb} \mathrm{O}_{3}$ without a corresponding loss of antioxidants in bronchoalveolar lavage (BAL) fluid sampled 1.5 hours after exposure. ${ }^{11}{ }^{12}$ In both cases, due to the early sampling time, these findings were found in the absence of airway neutrophilia. We were therefore interested to determine the manner, and to what extent, the redox state of RTLF is modified as a consequence of inflammation induced by $\mathrm{O}_{3}$. To examine this we sampled human RTLF by BAL 6 hours after exposure to air and $\mathrm{O}_{3}$. Six hours after exposure was selected as the sampling time as previous work by Schelegle et al had shown with a similar $\mathrm{O}_{3}$ dosage that this corresponds to the period of peak airway neutrophilia. Plasma samples were also obtained to determine whether alterations in the redox state of the fluid lining the respiratory tract impacted upon this remote compartment.

\section{Materials and methods}

Unless otherwise stated all chemicals were obtained from Sigma Chemicals, Poole, UK, or $\mathrm{BDH}$, Poole, UK.

SUBJECT GROUP

Eleven subjects were recruited into the study after placing advertisements in the local press. Subjects had a detailed consultation about the study and medical histories were taken and physical examinations performed before obtaining written informed consent. The study was performed in accordance with the guidelines of the Southampton joint ethics committee. All subjects were healthy non-smokers with no history of allergies or asthma. Subjects were instructed to refrain from dietary supplements or anti-inflammatory medications for the duration of the study. Also, exposures were rescheduled if subjects experienced any form of respiratory infection within a 6 week period before challenge dates. Before the start of the study, subjects were randomised into two groups, depending on whether they were to receive air or $\mathrm{O}_{3}$ as their first challenge. Notably there were no significant differences in the age or sex distribution between these two groups. Of the subjects who underwent exposure, paired samples of plasma and pulmonary function measurements were obtained from nine (all men). Two subjects failed to tolerate the bronchoscopy after the first challenge, and the subsequent exposure was abandoned. Of the nine remaining subjects (all men, mean age 28.1(4.9) years), paired BAL fluid samples were obtained from eight. Median (25th-75th percentiles) BAL fluid recoveries were relatively low for healthy subjects: $57.9 \%(48.5 \%-$ $61.0 \%)$ after air and $46.9 \%(42.6 \%-58.1 \%)$ after $\mathrm{O}_{3}$, but did not differ significantly between exposures.

STUDY DESIGN

Subjects were exposed on separate occasions to filtered air and $200 \mathrm{ppb} \mathrm{O}_{3}$. Successive exposures were separated by at least 6 weeks to minimise confounding carry over effects due either to the previous exposure or bronchoscopy. Controlled double blind crossover exposures were conducted. This design was used as we had previously shown large variations between people in antioxidant concentrations, which could obscure responses in a conventional cross sectional study. Total exposure time was 2 hours, during which subjects alternated between 15 minute cycles of exercise and rest. Exercise was performed with a bicycle ergometer with sufficient loading to produce an average minute ventilation of $30 \mathrm{l} / \mathrm{min}$. Plasma samples were obtained and spirometry performed before, immediately (0 hours) after, and at 6 hours after exposure. Blood samples were obtained and lung function performed immediately after challenge, before subjects prepared for the bronchoscopy procedure.

\section{EXPOSURE CONDITIONS}

The $\mathrm{O}_{3}$ was generated with an electrical discharge apparatus (Triogen ozone system, Glasgow, Model NVF 1/20 DE, manufactured by Ordup Maskin, Copenhagen), and was delivered to the subjects through a face mask fitted with a one way valve to isolate the supply at the mouth and prevent mixing of inspired and expired gases. The $\mathrm{O}_{3}$ concentration was measured every 20 seconds at the mask by means of a probe connected to a UV photometric $\mathrm{O}_{3}$ analyser (model 427, Rotork, Oxon, UK) with a precision of $20 \mathrm{ppb}$ and a linearity of $\pm 10 \mathrm{ppb}$. Mean (SD) $\mathrm{O}_{3}$ concentration for all nine challenges was 199.0 (9.0) ppb. Before delivery to the subject, air was passed through a humidifier (Fisher and Paykel Clinical Humidifier, Model MR 730, New Zealand) and conditioned to a relative humidity of $40 \%-60 \%$. Room temperature was maintained throughout exposures at $20-25^{\circ} \mathrm{C}$.

Minute ventilation was determined with pneumotachographs incorporated into the breathing circuit. The pressure drop across the stainless steel mesh of the pneumotachograph was transmitted to a pressure transducer. A bipolar analogue signal was then converted to a digital value and transmitted through a dedicated link to a computer, which averaged values over a 0.5 second sampling window.

\section{PULMONARY FUNCTION MEASUREMENTS}

Lung function measurements were obtained before air or $\mathrm{O}_{3}, 0$ hours after air or $\mathrm{O}_{3}$, and 6 hours after air or $\mathrm{O}_{3}$, with conventional spirometry. Spirometry was performed with the IOS master screen (Jaeger $\mathrm{GmbH}$, Germany) hand held heated mesh pneumotachograph. After a practice manoeuvre patients performed three conventional forced inspiratory measurements from residual volume, the best of which was used for analysis.

\section{BRONCHOSCOPY}

Fibreoptic bronchoscopy was performed 6 hours after exposure. All subjects received medication before exposure with application of a $4 \%$ lidocaine spray to the nasal airways and posterior pharyngeal wall, plus $0.6 \mathrm{mg}$ atropine and midazolam $2-10 \mathrm{mg}$ intravenously. The 
bronchoscope was introduced through the nose or mouth, based on the perceived comfort of the patient. Airways were anaesthetised with $1 \%$ lidocaine delivered through the bronchoscope before performing BAL. The BAL was performed from the right upper lobe (first challenge) and left upper lobe (second challenge). Lavage was performed by the instillation of $4 \times 40 \mathrm{ml}$ aliquots of saline $\left(37^{\circ} \mathrm{C}\right)$ followed by immediate aspiration into a siliconised trap kept on ice. Saline dwell time for each aliquot was therefore kept to an absolute minimum to prevent over sampling of the fluid lining the respiratory tract.

PREPARATION AND STORAGE OF PLASMA AND BAL FLUID SAMPLES

After collection, blood was divided between two heparinised tubes kept on ice, one of which contained $100 \mu \mathrm{l} 2 \mathrm{mmol} / \mathrm{l}$ butylated hydroxytoluene and desferrioxamine. Samples were then centrifuged at $2000 \mathrm{rpm}\left(4^{\circ} \mathrm{C}\right)$ for 10 minutes. Plasma was stored at $-80^{\circ} \mathrm{C}$ for up to 2 months in $1 \mathrm{ml}$ aliquots before analysis of concentrations of markers of antioxidants and oxidative damage. We have previously shown these moieties to be stable over this period under these storage conditions. Plasma samples protected with butylated hydroxytoluene and desferrioxamine were used for the measurement of the markers of oxidative damage, malondialdehyde and protein carbonyls, whereas those without additional antioxidants were used to determine endogenous antioxidant concentrations. The BAL fluid was strained with a metal gauze to remove mucus aggregates, and the recovered volume was recorded. The filtered aspirate was then separated into equal volume aliquots and centrifuged at $1000 \mathrm{rpm}\left(4^{\circ} \mathrm{C}\right)$ for 10 minutes. Cell free BAL fluid was then separated into aliquots for storage at $-80^{\circ} \mathrm{C}$. Aliquots of BAL fluid $(10 \mathrm{ml})$ for determination of malondialdehyde and protein carbonyls were mixed with $100 \mu \mathrm{l}$ butylated hydroxytoluene and desferrioxamine $(2 \mathrm{mmol} / \mathrm{l})$. Cell pellets were retained to count total and differential leucocytes.

MEASUREMENTS OF MARKERS OF ANTIOXIDANTS AND OXIDATIVE DAMAGE

Glutathione - reduced and disulphide formswere measured according to Baker et al. ${ }^{13}$ Detection limits for reduced glutathione and disulphide glutathione were established as 25 and $10 \mathrm{nmol} / 1$ respectively. Ascorbate and urate were measured simultaneously in plasma and BAL fluid with reverse phase high performance liquid chromatography (HPLC) with electrochemical detection. ${ }^{14}$ Minimum detectable concentrations were measured as $10 \mathrm{nmol} / \mathrm{l}$ (ascorbate) and $5 \mathrm{nmol} / \mathrm{l}$ (urate). Reverse phase HPLC with detection at $\mathrm{A}_{292} \mathrm{~nm}$ was used to measure of $\alpha$-tocopherol. ${ }^{15}$ Measurement of $\alpha$-tocopherol concentrations in BAL fluid required a preconcentration step. To achieve this, $3 \mathrm{ml}$ BAL fluid was placed in $5 \mathrm{ml}$ HPLC vials containing $100 \mu \mathrm{l}$ of an internal standard, tocopherol acetate $(2.75 \mathrm{mmol} / \mathrm{l})$. Vials were sealed with perforated caps and freeze dried over a 24 hour period. These samples were then reconstituted in $400 \mu \mathrm{H}_{2} \mathrm{O}$ by mixing, and transferred to $10 \mathrm{ml}$ glass centrifugation tubes. Two $\mathrm{ml}$ hexane was then added and samples were mixed thoroughly for a further 5 minutes before centrifugation: $3000 \mathrm{rpm}$ for 5 minutes $\left(4^{\circ} \mathrm{C}\right)$. The upper hexane layer was decanted and dried down under $\mathrm{N}_{2}$. Finally, before analysis, samples were resuspended in $200 \mu \mathrm{l}$ methanol and thereafter treated identically with plasma samples. Recovery of the internal standard after this sample concentration step was $50 \%-75 \%$. Total protein was measured with the bicinchonoic acid method of Smith et $a l,{ }^{16}$ and plasma total sulphydryls with the method of Waynor et al. ${ }^{17}$ The HPLC measurement of malondialdehyde was based on the method of Chirico ${ }^{18}$ as previously described. ${ }^{19}$ The detection limit of this assay is $5 \mathrm{nmol} / \mathrm{l}$. Protein carbonyls were measured according to Reznick et al. ${ }^{20}$ The measurements of protein carbonyls in BAL fluid required a preconcentration step in which $10 \mathrm{ml}$ was concentrated to $0.7 \mathrm{ml}$ with a Centriprep-10 centrifugal concentrator (Millipore, UK), centrifuged twice at $3000 \mathrm{~g}\left(4^{\circ} \mathrm{C}\right)$, firstly for 30 minutes, after which the liquid in the concentrator reservoir was decanted, and finally for a further 10 minutes. Samples were then treated in the same manner as plasma.

\section{BAL FLUID TOTAL AND DIFFERENTIAL CELL}

COUNTS AND MYELOPEROXIDASE

Cell counts were performed on resuspended cell pellets $\left(10^{6}\right.$ cells $/ \mathrm{ml}$ in phosphate buffered saline). The total numbers of cells in lavage fluid were counted in a Burker chamber. Cytocentrifuge samples were then prepared with $5 \times 10^{4}$ cells per slide at $1000 \mathrm{rpm}$ for 5 minutes. Differential counts (400 cells per slide) were then performed on cytospin preparations stained with May-Grunwald Giemsa. Myeloperoxidase was measured in BAL fluid with an immunoassay kit commercially available from OXIS (Portland, OR, USA).

DATA MANIPULATION AND STATISTICAL ANALYSES Determination of antioxidant partition ratios To consider whether $\mathrm{O}_{3}$ exposure induced changes in the relation between the antioxidant pools in plasma and fluid lining the respiratory tract, airway partitioning ratios, ([plasma $]_{6 \mathrm{~h} \text {-after }}$ $\left./[\mathrm{BAL}]_{6 \mathrm{~h}-\text { after exposure }}\right)$ were calculated 6 hours after challenge by air and $\mathrm{O}_{3}$. Airway partitioning ratios were obtained for ascorbate, urate, $\alpha$-tocopherol, and total protein. Glutathione was not detected in plasma in this study so the partition ratio for this antioxidant is not available in this study.

\section{Statistics}

The BAL fluid data were not normally distributed, nor could they be adequately transformed, hence redox marker concentrations and inflammatory variables after exposures to air and $\mathrm{O}_{3}$ were analysed with the Wilcoxon signed rank test. Data are expressed throughout as median values with (25th-75th percentiles). Rejection of the null hypothesis-that no significant differences occurred in these variables as a consequence of exposure to 
Table 1 BAL fluid differential cell counts obtained from healthy subjects 6 hours after a 2 hour exposure to 200 ppb $O_{3}$ or filtered air

\begin{tabular}{|c|c|c|c|c|c|}
\hline & Macrophages & Neutrophils & Eosinophils & Lymphocytes & Epithelial cells \\
\hline \multicolumn{6}{|c|}{ Differential cell count ( $\%$ of total cells): } \\
\hline \multirow[t]{2}{*}{ After air } & $90.4(88.0-91.0)$ & $3.6(1.8-5.6)$ & $0.0(0.0-0.2)$ & $4.2(2.6-5.8)$ & $1.8(1.4-3.5)$ \\
\hline & $<0.05$ & $<0.05$ & NS & NS & $<0.05$ \\
\hline \multirow{2}{*}{\multicolumn{6}{|c|}{ Total cells $/ \mathrm{ml}\left(\times 10^{3}\right)$ : }} \\
\hline & & & & & \\
\hline After air & $\begin{array}{c}250.7(127.4-298.3) \\
p=0.08\end{array}$ & $\begin{array}{c}6.4(2.9-14.0) \\
\mathrm{p}=0.07\end{array}$ & $\begin{array}{c}0.0(0.0-0.3) \\
\text { NS }\end{array}$ & $\begin{array}{c}8.6(4.0-15.3) \\
p=0.08\end{array}$ & $\begin{array}{c}4.6(2.9-8.3) \\
\text { NS }\end{array}$ \\
\hline After $\mathrm{O}_{3}$ & $99.1(68.6-176.8)$ & $14.0(12.2-15.8)$ & $0.0(0.0-0.2)$ & $2.8(2.4-5.2)$ & $10.8(4.4-11.2)$ \\
\hline
\end{tabular}

Data presented as median values with 25 th and 75 th percentiles $(n=7)$. Significant deviations from the air control values after exposure to $\mathrm{O}_{3}$ were measured with Wilcoxon's matched pairs signed rank test. Results of these analyses are shown for each paired response above.

$\mathrm{O}_{3}$-was assumed at the $5 \%$ level. By contrast with the situation in BAL fluid, plasma moieties were normally distributed (measured with the Shapiro-Wilks normality test) and are therefore expressed throughout as means (SD). As multiple time points were considered, plasma data were analysed with a repeated measures two way ANOVA with factors for treatment; air and $\mathrm{O}_{3}$, and time; before, immediately after, and 6 hours after exposure. All pairways comparisons between groups were conducted with the StudentNewman-Keuls procedure. Lung function data were also non-parametric and time and treatment factors were considered. Data were therefore analysed with Quades two way analysis of varience (ANOVA) with multiple comparisons performed with rank sums and the $t$ distribution. Correlation analysis to determine the degree of association between variables was performed with Spearman's rank order correlation. When confounding influences between variables were found these were resolved with partial correlation analysis. All analyses were performed with the Unistat (Unistat, London, UK) and SPSS (SPSS, Chicago, USA) statistical packages on a Windows based PC platform.

Details of correlation analyses

Correlation analysis between BAL fluid redox markers and inflammatory variables were limited to a consideration of those variables in which significant effects attributable to $\mathrm{O}_{3}$ had been found, or where clear trends could be inferred. The degree of association was assessed with absolute values 0 and 6 hours after challenge with air and $\mathrm{O}_{3}$. The absolute values for forced expiratory volume in one second $\left(\mathrm{FEV}_{1}\right)$ and forced vital capacity (FVC) at 0 and 6 hours after exposure were used to indicate pulmonary function responses, the change in pulmonary functions across the intervals before exposure to 0 or 6 hours after exposure to air and $\mathrm{O}_{3}$.

\section{Results}

TOTAL AND DIFFERENTIAL CELL COUNTS

Total and differential cell counts in paired BAL fluid samples were obtained from seven subjects (table 1). Although not significant, a trend toward a decrease in total BAL fluid cell numbers was noted after $\mathrm{O}_{3}$ (median (25th75 th percentile) $0.3(0.1-0.3) \times 10^{6}$ cells $/ \mathrm{ml}$ after air $v 0.1(0.1-0.2) \times 10^{6}$ cells $/ \mathrm{ml}$ after $\left.\mathrm{O}_{3}\right)$. This decrease predominately reflected reduced mac- rophage $\left(-63.9(-252.6-1.2) \times 10^{3}\right.$ cells $/ \mathrm{ml}$; $\mathrm{p}=0.08)$ and lymphocyte $-6.9(-10.4-1.2) \times 10^{3}$ cells $/ \mathrm{ml} ; \mathrm{p}=0.08)$ numbers. Conversely, a mild neutrophilia was apparent $(+10.6(1.8-11.2) \times$ $10^{3}$ cells $\left./ \mathrm{ml} ; \mathrm{p}=0.07\right)$. Of note, total cell, macrophage, and lymphocyte numbers after $\mathrm{O}_{3}$ (not after air) were all inversely related to neutrophil numbers (neutrophils $v$ total cells $(R=-0.77$, $\mathrm{p}<0.05), v$ macrophages $(R=-0.79, \mathrm{p}<0.05)$, and $v$ lymphocytes $(R=-0.75, \mathrm{p}<0.05))$.

To acertain whether airway neutrophils were activated, myeloperoxidase concentrations were measured in BAL fluid. Although not significant, a trend $(p=0.08)$ towards an increased myeloperoxidase concentration was apparent (1.1 (1.0-1.2) $\mathrm{ng} / \mathrm{ml}$ after air $v 4.4(1.0-6.9)$ $\mathrm{ng} / \mathrm{ml}$ after $\mathrm{O}_{3}$ ). To elucidate whether this reflected actual cell activation or simply increased neutrophil numbers, myeloperoxidase concentrations were expressed per neutrophil. When this was done no evidence of activation was apparent (median (25th-75th percentile) $0.1(0.1-0.3) \mathrm{pg} /$ neutrophil after air v $0.2(0.1-0.3) \mathrm{pg} /$ neutrophil after $\left.\mathrm{O}_{3}\right)$. Myeloperoxidase expressed per BAL fluid volume, or per neutrophil, was inversely related to both total cell numbers and macrophages after $\mathrm{O}_{3}$ (myeloperoxidase $v$ macrophages $(R=-0.93$, $\mathrm{p}=0.001), v$ total cell numbers $(R=-0.96$, $\mathrm{p}<0.001$ ), and myeloperoxidase or neutrophils $v$ macrophages $(R=-0.68, \mathrm{p}<0.05)$, $v$ total cell numbers $(R=-0.74, \mathrm{p}<0.05))$. No associations were found 6 hours after air challenge. Similarly, if the change in these variables (after ozone minus after air values) were compared, significant negative correlations were found (data not shown), indicating that total cell, macrophage, and lymphocyte numbers fell more in those people with the greatest increase in myeloperoxidase concentration in $\mathrm{BAL}$ fluid.

\section{BAL FLUID ANTIOXIDANT AND OXIDATIVE DAMAGE} MARKERS

As reported previously, ${ }^{19} 2122$ considerable between subject variations in antioxidant concentrations in BAL fluid were found (table 2). Baseline (after air) concentrations of the oxidation markers, malondialdehyde, and protein carbonyls were low, below detectable limits in several subjects, and consequently there was also considerable between subject variation (data not shown). Glutathione disulphide was not detected in any BAL fluid samples after either exposure. 
Table 2 Bronchoalveolar lavage fluid antioxidant concentrations 6 hours after a 2 hour exposure to either air or $200 \mathrm{ppb} \mathrm{O}_{3}$

\begin{tabular}{|c|c|c|}
\hline \multirow[b]{2}{*}{ Antioxidant } & \multicolumn{2}{|c|}{6 Hours after exposure } \\
\hline & Air & $\mathrm{O}_{3}$ \\
\hline Ascorbate $(\mu \mathrm{mol} / \mathrm{l})$ & $\begin{array}{c}0.3(0.2-1.2) \\
\mathrm{p}=0.008\end{array}$ & $0.1(0.0-0.3)$ \\
\hline Urate $(\mu \mathrm{mol} / \mathrm{l})$ & $\begin{array}{c}1.7(0.1-2.5) \\
\text { NS }\end{array}$ & $2.4(1.5-3.0)$ \\
\hline Glutathione $(\mu \mathrm{mol} / \mathrm{l})$ & $\begin{array}{c}1.5(1.1-2.7) \\
\text { NS }\end{array}$ & $1.4(0.9-2.5)$ \\
\hline$\alpha$-Tocopherol (nmol/l) & $\begin{array}{c}30.0(8.0-43.8) \\
\text { NS }\end{array}$ & $38.1(22.6-47.5)$ \\
\hline
\end{tabular}

All values are expressed as median values with 25 th and 75 th quartiles. Rejection of the null hypothesis was assumed when $\mathrm{p}<0.05$ with the Wilcoxon's signed rank test. In all cases $\mathrm{n}=8$ (subjects 2-9).

Of the antioxidants examined, only ascorbate altered as a consequence of exposure to $\mathrm{O}_{3}$, falling in all eight subjects from whom paired BAL fluid samples were obtained $(-0.2$ $(-0.9$ to -0.1$) \mu \mathrm{mol} / 1)$, a fall of $66.7 \%$ compared with the median concentration after air (table 2). Notably, in two subjects ascorbate fell to non-detectable concentrations 6 hours after $\mathrm{O}_{3}$. Two subjects had high ascorbate concentrations after air $(2.6$ and $1.8 \mu \mathrm{mol} / \mathrm{l})$ compared with the other members of the group. To exclude the possibility that the fall in ascorbate after $\mathrm{O}_{3}$ was disproportionately influenced by these two responses, analysis was repeated without their paired data. This approach did not alter the effect, ascorbate concentrations remained significantly depressed after $\mathrm{O}_{3}$ challenge $(p<0.05)$. The effect also persisted irrespective of how the data were expressed: either corrected for recovery of BAL fluid, (median (25th-75th percentile) 0.6 (0.3-2.2) $\mu \mathrm{mol} / 1$ after air $v 0.2(0.1-0.6) \mu \mathrm{mol} / 1$ after $\mathrm{O}_{3}$, $\mathrm{p}<0.01$; or with total protein as a denominator, $2.6(1.4-5.1) \mathrm{nmol} / \mathrm{mg}$ after air $v 0.8(0.1-1.2)$ $\mathrm{nmol} / \mathrm{mg}$ after $\left.\mathrm{O}_{3}, \mathrm{p}<0.01\right)$. We do not favour the use of either of these corrections as in our experience they only introduce greater and effectively random variation into BAL fluid measurements.

Although $\mathrm{O}_{3}$ exposure did not result in an increased concentration of markers of oxidation (malondialdehyde or protein carbonyls) in BAL fluid, some evidence of altered epithelial permeability was apparent. Total protein concentrations were increased in seven of eight subjects after exposure to $\mathrm{O}_{3}$, although nonsignificant $(0.15(0.09-0.25) \mathrm{mg} / \mathrm{ml}$ after air, $v$ $0.24(0.20-0.36) \mathrm{mg} / \mathrm{ml}$ after $\left.\mathrm{O}_{3} ; \mathrm{p}=0.08\right)$.

Table 3 Antioxidant partition ratios indicative of the relation between plasma and RTLF concentrations 6 hours after air (control) and $\mathrm{O}_{3}$ exposures

\begin{tabular}{llcl}
\hline Antioxidant & 6 h After air & 6 h After $O_{3}$ & $p$ Value \\
\hline Ascorbate & $40.3(17.6-137.1)$ & $170.7(39.3-760.9)$ & $<0.05$ \\
Urate & $120.5(82.5-215.4)$ & $92.9(66.4-146.8)$ & $\mathrm{NS}$ \\
Glutathione & $\mathrm{ND}$ & $\mathrm{ND}$ & - \\
$\alpha$-Tocopherol & $568.0(400.8-2467.9)$ & $436.6(367.0-720.6)$ & $\mathrm{NS}$ \\
Total protein & $366.3(273.0-751.0)$ & $276.8(205.1-308.0)$ & 0.08 \\
\hline
\end{tabular}

All values are dimensionless representing the ratio of concentrations of plasma/BAL fluid, $n=8$. Glutathione partition ratio was not determined (ND) as plasma concentrations were low or not detectable.
PLASMA ANTIOXIDANTS AND MARKERS OF OXIDATIVE DAMAGE

Antioxidants (ascorbate, urate, total sulphydryls, and $\alpha$-tocopherol) and concentrations of markers of oxidative damage (malondialdehyde and protein carbonyls) were measured in plasma samples obtained from subjects, before exposure, 0 hours after exposure, and 6 hours after exposure. Mean (SD) baseline antioxidant concentrations were broadly in line with those reported previously with no significant differences between concentrations before air and $\mathrm{O}_{3}$ (ascorbate 26.2 (12.8) and 21.6 (9.4) $\mu \mathrm{mol} / 1$; urate 233.2 (37.9) and 246.2 (50.2) $\mu \mathrm{mol} / 1$; total sulphydryls $0.6(0.1)$ and $0.7(0.2)$ $\mathrm{mmol} / \mathrm{l}$; and $\alpha$-tocopherol 16.6 (1.3) and 15.9 (2.1) $\mu \mathrm{mol} / 1$, respectively). As with the results from BAL fluid, only ascorbate seemed to be significantly altered by exposure to $\mathrm{O}_{3}$, decreasing significantly $(\mathrm{p}<0.05) 6$ hours after $\mathrm{O}_{3}$, compared with concentrations before exposure (15.1 (9.3) $v 21.6$ (9.4) $\mu \mathrm{mol} / 1$ ). The magnitude of this loss was small when the parallel response over the interval before exposure to 6 hours after exposure to air was considered $(-22.2 \%(22.2 \%)$ in air $v-29.1 \%(33.7 \%)$ in $\mathrm{O}_{3}$ ). This decrease seemed to reflect a response after exposure, as no loss was found immediately after $\mathrm{O}_{3}$ compared with before exposure. Importantly, no quantitative relation between the loss of ascorbate from the pools in plasma and fluid lining the respiratory tract was noted. Exposure to ozone did not result in an increase in concentrations of either plasma malondialdehyde or protein carbonyls (data not shown).

PARTITION RATIOS

Antioxidants (ascorbate, urate, and $\alpha$-tocopherol) and total protein partition ratios: ([plasma] 6 hours after $\mathrm{O}_{3}$ or air)/([BAL fluid] 6 hours after $\mathrm{O}_{3}$ or air), are given in table 3 . ascorbate partition ratios were found to increase significantly $(4.2$-fold, $\mathrm{p}<0.05)$ after exposure to $\mathrm{O}_{3}$, consistent with an increased concentration of antioxidant in plasma relative to fluid lining the respiratory tract. This was largely attributable to the decrease in the pool of ascorbate in the fluid lining the respiratory tract. A decreased trend for the total protein partitioning ratio was found $(\mathrm{p}=0.08)$.

ANALYSIS OF THE CORRELATION BETWEEN INFLAMMATION AND ANTIOXIDANTS

Significant positive associations between the concentration of ascorbate with total cell and macrophage numbers in BAL fluid were found after $\mathrm{O}_{3}$ challenge $(R=0.72, \mathrm{p}<0.05$, and $R=0.66$, $\mathrm{p}=0.05$, respectively). Similar relations were not noted after the control exposure to air. In agreement with these findings, significant negative associations for these cell variables were also found with the ascorbate partition ratio after exposure to $\mathrm{O}_{3}: v$ total cells $(R=-0.74, \mathrm{p}<0.05)$, and $v$ macrophages $(R=-$ $0.79, \mathrm{p}<0.05)$. In contrast, only the ascorbate partition ratio was associated with myeloperoxidase after $\mathrm{O}_{3}$ challenge (ascorbate partition ratio $v$ myeloperoxidase or neutrophils $(R=0.68, \mathrm{p}<0.05))$. Notably, no relations between lymphocyte and neutrophils numbers 
Table 4 Correlation coefficients(Rs) resulting from analyses between $F E V_{1}$ and $F V C$ values at 0 and 6 hours after exposure to air and $O_{3}$ (unweighted, and weighted for values before exposure) and a range of BAL fluid variables, measured at 6 hours after air and $\mathrm{O}_{3}$ challenge: correlation coefficients (Rs) and $p$ values are illustrated for each significant interaction

\begin{tabular}{|c|c|c|c|c|c|c|c|c|}
\hline \multirow[b]{2}{*}{ Variable } & \multicolumn{4}{|l|}{$F E V_{1}$} & \multicolumn{4}{|l|}{$F V C$} \\
\hline & $\operatorname{Air}(0 h)$ & $\mathrm{O}_{3}(\mathrm{Oh})$ & $\operatorname{Air}(6 h)$ & $\mathrm{O}_{3}(6 \mathrm{~h})$ & $\operatorname{Air}(0 h)$ & $\mathrm{O}_{3}(0 \mathrm{~h})$ & $\operatorname{Air}(6 h)$ & $\mathrm{O}_{3}(6 h)$ \\
\hline \multicolumn{9}{|l|}{ Unweighted } \\
\hline Ascorbate & NS & $0.77^{\star}$ & NS & NS & NS & $0.71^{\star}$ & NS & NS \\
\hline Urate & NS & $-0.76^{\star}$ & NS & $-0.67^{\star}$ & NS & $-0.93^{\star \star \star}$ & NS & $-0.81^{\star \star}$ \\
\hline Ascorbate partition ratio & $-0.81^{\star \star}$ & $-0.88^{\star \star}$ & $-0.83^{\star \star}$ & NS & NS & $-0.74^{\star}$ & NS & NS \\
\hline Urate partition ratio & NS & $0.62^{\star}$ & NS & NS & NS & $0.79^{\star}$ & NS & $0.71^{\star}$ \\
\hline Macrophages & NS & $0.68^{\star}$ & NS & NS & NS & NS & NS & NS \\
\hline Neutrophils & NS & NS & NS & NS & NS & NS & NS & NS \\
\hline Myeloperoxidase & NS & NS & NS & NS & NS & NS & NS & NS \\
\hline Neutrophils/Myeloperoxidase & NS & $-0.71^{\star}$ & NS & NS & NS & $-0.90^{\star \star}$ & NS & $-0.86^{\star \star}$ \\
\hline \multicolumn{9}{|l|}{ Weighted: } \\
\hline Ascorbate & NS & $0.89^{\star \star}$ & NS & NS & NS & $0.77^{\star \star}$ & $0.69^{\star}$ & NS \\
\hline Urate & NS & $-0.71^{\star}$ & NS & $-0.69^{\star}$ & NS & $-0.81^{\star \star}$ & NS & $-0.72^{\star}$ \\
\hline Ascorbate partition ratio & NS & $-0.95^{\star \star \star}$ & $-0.63^{\star}$ & NS & NS & $-0.86^{\star \star}$ & NS & NS \\
\hline Urate partition ratio & NS & $0.76^{\star}$ & NS & NS & NS & $0.76^{\star}$ & NS & $0.86^{\star \star}$ \\
\hline Macrophages & NS & $0.71^{\star}$ & NS & NS & NS & NS & NS & $0.74^{\star}$ \\
\hline Neutrophils & NS & NS & NS & $-0.67^{\star}$ & NS & NS & NS & $-0.96^{\star \star \star}$ \\
\hline Myeloperoxidase & NS & NS & NS & NS & NS & NS & NS & NS \\
\hline Neutrophils/Myeloperoxidase & NS & $-0.75^{\star}$ & NS & NS & NS & $-0.83^{\star \star}$ & NS & $-0.75^{\star}$ \\
\hline
\end{tabular}

${ }^{\star} \mathrm{p}<0.05 ;{ }^{\star \star} \mathrm{p}<0.01 ;{ }^{\star \star \star} \mathrm{p}<0.001$ with Spearman's rank order correlation. $\mathrm{n}=8$ For all comparisons with BAL antioxidants, and partition ratios, and $\mathrm{n}=7$ for BAL differential cell counts.

or their markers of activation were found after either exposure. These correlations were found after controlling for any underlying confounding influence arising due to urate. Urate was included in these analyses as (a) RTLF ascorbate and urate concentrations are known to be positively correlated (unpublished observations), and (b) previous work has shown it to be significantly depleted by $\mathrm{O}_{3}$ during the actual exposure period. It was therefore possible that apparent associations between ascorbate and inflammatory markers could be spurious, reflecting an underlying association between these variables and urate. We found that urate concentrations after $\mathrm{O}_{3}$ (allowing for the ascorbate effect) were also significantly associated with total cell numbers $(R=-0.68, \mathrm{p}<0.05)$, macrophages $(R=-0.68, \mathrm{p}<0.05)$, and myeloperoxidase or neutrophils $(R=0.75$, $\mathrm{p}<0.05)$.

\section{ANALYSIS OF CORRELATIONS WITH PULMONARY} FUNCTION

$\mathrm{No}_{3}$ dependent decrease in FVC or FEV was found. The FVC responses (air $v \mathrm{O}_{3}$ ) from before exposure to 0 hours after exposure being $-0.06(0.11) v-0.13(0.27) 1$; and from before exposure to 6 hours after exposure, -0.07 $(0.12) v+0.01(0.17) 1$, respectively. Comparable $\mathrm{FEV}_{1}$ responses were $-0.04(0.12) v-0.07$ (0.25) 1 and $-0.01(0.09) v+0.05(0.21) 1$ from 0 hours to 6 hours after exposure. Despite the absence of a clear group effect, considerable variations between people were found. To ascertain whether the size of these individual decrements represented an important determinant of the magnitude of the subsequent inflammatory and antioxidant response, correlation analyses were performed with the values 0 and 6 hours after air and $\mathrm{O}_{3}$. As lung function values were available both before and after exposure, the response over the time from before exposure to 0 and 6 hours after exposure were also considered. The number of variables tested were limited to ascorbate and urate concentrations and partition ratios in BAL fluid, macrophage and neutrophil numbers in BAL fluid, and myeloperoxidase expressed per volume of recovered BAL fluid and per neutrophil (table 4). In general, both the absolute values of $\mathrm{FVC}$ and $\mathrm{FEV}_{1}$ after $\mathrm{O}_{3}$ and their responses during the time from before exposure to 0 or 6 hours after exposure were negatively correlated with urate and myeloperoxidase or neutrophil concentrations and ascorbate partition ratio, and positively correlated with ascorbate concentration, macrophage numbers, and the urate partition ratio. These effects seemed more pronounced when lung function values and responses at 0 hours after exposure, or the time before exposure to 0 hours after exposure were used, suggesting that the magnitude of the pulmonary response was predictive of the subsequent inflammatory and antioxidant response. Notably, significant associations with FVC seemed to be more persistent at the 6 hours after exposure than did those with $\mathrm{FEV}_{1}$.

\section{Discussion}

Previously, we failed to show antioxidant consumption in the distal fluid lining the respiratory tracts of healthy subjects 1.5 hours after $\mathrm{O}_{3}$ (200 ppb for 2 hours). ${ }^{12}$ We interpreted this finding to indicate that $\mathrm{O}_{3}$, at this dose, did not compromise antioxidant status, or that, even at this early time after exposure, effects directly induced by $\mathrm{O}_{3}$ had fully resolved. Importantly, no evidence of airway inflammation was apparent at 1.5 hours after exposure. In the current study we therefore examined whether inflammation induced by $\mathrm{O}_{3}$ would impact upon RTLF antioxidant state. To achieve this we performed BAL at 6 hours after exposure, a time previously shown to correspond to maximal neutrophil influx into human airways after $\mathrm{O}_{3}{ }^{9}$ As neutrophils represent the predominant source of reactive oxygen species in the lung during inflammatory episodes ${ }^{10}$ we used this cell and its product, myeloperoxidase as temporal markers of the inflammatory response. The primary aim of this study was therefore to relate changes in these variables to alterations in RTLF antioxidant state. 
Our main findings were: (a) a significant decrease in ascorbate in BAL fluid 6 hours after $\mathrm{O}_{3}$ challenge $(\mathrm{p}<0.01)$, contemporaneous with, although not quantitatively related to, a small decrease in ascorbate in plasma $(\mathrm{p}<0.05)$ over the period after exposure. (b) Trends indicating increased neutrophil numbers $(p=0.07)$ and myeloperoxidase concentrations $(\mathrm{p}=0.08)$ in BAL fluid recovered from subjects after exposure to $\mathrm{O}_{3}$. (c) Reduced macrophage and lymphocyte numbers after exposure to $\mathrm{O}_{3}$ which were inversely related to neutrophils $(R=-0.79)$ and myeloperoxidase increases expressed per volume of recovered BAL fluid $(R=-0.93)$, or per neutrophil $(R=-0.68)$. (d) Total cell and macrophage numbers after exposure to $\mathrm{O}_{3}$ were positively associated with ascorbate concentrations in BAL fluid ( $R=0.72$ and $R=0.66$, respectively). (e) Alterations in concentrations of ascorbate in plasma and fluid lining the respiratory tract resulted in a significant $(p<0.05)$ decrease in the ascorbate partitioning ratio. $(f)$ No decrements were found in $\mathrm{FEV}_{1}$ and FVC after exposure to $\mathrm{O}_{3}$, but evidence that the magnitude of individual responses were predictive of ascorbate and myeloperoxidase per neutrophil concentrations as well as macrophage numbers 6 hours after $\mathrm{O}_{3}$.

We found a significant loss of ascorbate in the fluid lining the respiratory tract 6 hours after the end of the exposure to $\mathrm{O}_{3}$. The extent to which this reflected a direct effect induced by $\mathrm{O}_{3}$ that had failed to resolve, or an inflammatory effect was difficult to ascertain. Although increased neutrophil numbers and myeloperoxidase concentrations were found after exposure to $\mathrm{O}_{3}$, these were not significant and neither was quantitatively related to either ascorbate concentration in the fluid lining the respiratory tract or its partition ratio. Previously we found no impact of a $200 \mathrm{ppb} \mathrm{O}_{3}$ (2 hour) challenge on ascorbate concentration in fluid lining the respiratory tract 1.5 hours after exposure. ${ }^{12}$ Notably at this early time after exposure there was no evidence of neutrophilic inflammation. Further, as both ascorbate and urate had similar reactivities toward $\mathrm{O}_{3},{ }^{23}{ }^{24}$ had $\mathrm{O}_{3}$ been directly responsible for the loss of ascorbate, an even more pronounced effect on urate would have been expected, as urate baseline concentrations were 5.4-fold those of ascorbate. The absence of urate depletion may therefore be taken as supporting the view that the loss of ascorbate was not directly related to $\mathrm{O}_{3}$.

The importance of ascorbate in conferring protection against oxidative stress derived from inflammatory cells is well established. In the plasma of humans exposed to phorbolmyristate activated neutrophils, ascorbate represents the first tier of defence against reactive oxygen species derived from the neutrophils. ${ }^{25}$ Urate, thiol, and lipid oxidation only occur in this model when ascorbate is completely depleted. Ascorbate has also been shown to represent the primary antioxidant in plasma of people exposed to $\mathrm{H}_{2} \mathrm{O}_{2}$ and $\mathrm{O}_{2}{ }^{26}$ or the gas phase oxidants present in cigarette smoke. ${ }^{27}$ Ascorbate is also compromised in plasma and fluid lining the respiratory tract of subjects with a range of chronic and acute pulmonary condi- tions associated with a heavy lung burden of inflammatory cells. ${ }^{1928}{ }^{29}$ Further, evidence for a protective role for ascorbate against injury induced by $\mathrm{O}_{3}$ has been shown in guinea pigs, in which epithelial injury is exacerbated in animals deficient in ascorbate. ${ }^{30}$ Ascorbate has also been implicated in the development of adaptation, as ascorbate concentration increases in the lungs of rats exposed to repeated subacute exposures to $\mathrm{O}_{3}$, contemporaneous with attenuation of the subsequent response to $1 \mathrm{ppm} \mathrm{O}_{3}{ }^{31}$

The lack of a quantitative relation between ascorbate concentration in the fluid lining the respiratory tract and neutrophil numbers or the markers of their activation after $\mathrm{O}_{3}$ is therefore perplexing. Several possibilities may, however, explain this lack of an association. Firstly, due to subject dropout the current study was under-powered ( $n=7$, for correlation analysis between antioxidants and inflammatory cells) and that unless these associations were profound they were unlikely to be detected. A second possible explanation is that although two processes may be mechanically related they could have different temporal profiles - that is, activation of neutrophils may have been maximal before the 6 hour bronchoscopy point and the loss of ascorbate may be related to this, rather than the absolute number of cells or state of activation 6 hours after exposure. Thirdly, the loss of ascorbate in the current study may not be related to reactive oxygen species derived from neutrophils or other contemporaneous processes may have obscured this relation. Neutrophils take up ascorbate (in its oxidised form as dehydroascorbate) before activation, ${ }^{34}$ to protect themselves from their own respiratory burst. It is possible therefore that cellular sequestration of ascorbate in the fluid lining the respiratory tract may also have contributed to decreased concentrations after exposure to $\mathrm{O}_{3}$.

Although neutrophil numbers increased after exposure to $\mathrm{O}_{3}$, total BAL fluid cells decreased, predominately due to losses in the macrophage and lymphocyte populations. Decreased numbers of total cells and macrophages in BAL fluid have been reported previously, ${ }^{12}{ }^{35}$ but to our knowledge this is the first report of decreased lymphocyte numbers in BAL fluid after exposure to $\mathrm{O}_{3}$. Whether this reflects a direct toxic effect of $\mathrm{O}_{3}$, or a consequence of inflammation induced by $\mathrm{O}_{3}$, resulting in cell death or altered cell adhesion properties making cells more difficult to wash from the airway surfaces cannot be differentiated in the current study. Importantly, the number of macrophages after $\mathrm{O}_{3}$ correlated positively with ascorbate in BAL fluid, and negatively with neutrophil numbers, myeloperoxidase, and myeloperoxidase per neutrophil concentrations. These findings infer that the loss of macrophages was related to the degree of airway neutrophilia, with ascorbate being protective against this effect. Although this is consistent with the results, it is notable that a similar decrease in macrophage numbers has been found at 1.5 hours after exposure in the absence of airway inflammation. Consequently, unless macrophages are sensitive to both $\mathrm{O}_{3}$ and 
reactive oxygen species derived from neutrophils, with a biphasic loss of cells, it is possible that these two processes are simply proportionate and parallel to the earlier $\mathrm{O}_{3}$ insult.

We found a small but significant loss of plasma ascorbate after $\mathrm{O}_{3}$ in the period after exposure. As subjects were not permitted food from their reception into the department on the day of the study until after the anaesthesia had worn off about 10 hours later, this may simply represent a fasting artifact. However, the crossover control design of this study should have eliminated this possibility, and notably ascorbate concentrations in plasma did not fall significantly over the air control arm of this study. Whether this decrease represents evidence of movement of ascorbate from the plasma pool to offset its loss from the fluid lining the respiratory tract, or the consequence of a more systemic oxidative insult is not clear, as systemic markers of inflammation were not followed up. The significant alteration in the ascorbate partition ratio in favour of the plasma pool would, however, imply a greater concentration gradient between the two compartments conducive to a net movement of ascorbate to the fluid lining the respiratory tract. These results may therefore reflect an adaptive response to re-establish ascorbate concentrations in the fluid lining the respiratory tract, a response which will impact upon the plasma pool, although the absolute change may be of little systemic relevance.

Clearly, the capacity to replenish the redox balance of the fluid lining the respiratory tract, and the rate and efficiency of such a process is likely to represent an important determinant of individual sensitivity. Of note, those people displaying the greatest falls in ascorbate in the fluid lining the respiratory tract did not have the largest decreases in the plasma. This finding suggests that the process is not simple and is likely to be modified not only by individual state of airway inflammation, but also by alterations in airway permeability. Notably, the timing of this response (after exposure) is consistent with our view that the oxidative insult found arises as a function of the developing inflammatory response.

The fact that $\mathrm{O}_{3}$ did not elicit decrements in $\mathrm{FEV}_{1}$ or FVC in the current study probably reflects the moderate work rate used. Previous studies have shown significant decrements in FVC and $\mathrm{FEV}_{1}$ in healthy subjects at lower $\mathrm{O}_{3}$ concentrations than used here. These studies, however, used work rates or exposure durations that delivered a total dose to the subject in excess of that in the current study. ${ }^{1}$ Despite the lack of an overall effect, considerable individual heterogeneity in responsiveness was found. Correlations were performed to investigate whether individual pulmonary responses were related to the subsequent magnitude of inflammatory and antioxidant responses. Previous studies had shown some evidence of an inverse relation (positive correlation) between initial decrements in lung function $\left(\mathrm{FEV}_{1}\right)$ and airway neutrophilia 6-18 hours after $\mathrm{O}_{3}$ challenge ${ }^{9}{ }^{32}$ - that is, large initial decrements associated with attenuated neutrophilia. No such relation was found in the current study for $\mathrm{FEV}_{1}$ or FVC measured 0 hours after exposure; however a negative correlation $(R=-0.96)$ between the FVC response during the time from before exposure to 6 hours after exposure and neutrophil numbers was found. Although no clear associations between lung function values and responses with neutrophil numbers and myeloperoxidase concentrations were found, when myeloperoxidase concentrations were expressed per neutrophil, significant negative correlations were noted with $\mathrm{FEV}_{1}$ at 0 hours after exposure, and FVC at both 0 and 6 hours after exposure to $\mathrm{O}_{3}$. These findings contrast with those already outlined, as subjects with the greatest decrements in $\mathrm{FEV}_{1}$ and FVC seemed to have the more active neutrophil populations. Conversely, significant positive correlations were found between $\mathrm{FEV}_{1} 0$ hours after exposure with macrophage numbers and ascorbate concentrations after exposure to $\mathrm{O}_{3}$ indicating that large decrements in $\mathrm{FEV}_{1}$ were predictive of decreased macrophages and ascorbate 6 hours after exposure to $\mathrm{O}_{3}$. Decrements were largest in those people in whom no detectable ascorbate was found after $\mathrm{O}_{3}$. A proportionate but opposite association was noted for urate. Increased movement of urate into fluid lining the respiratory tract has been found after exposure to $\mathrm{O}_{3}$ and this has been proposed to represent a protective mechanism. ${ }^{1133}$ It is notable in the present study that urate concentrations after $\mathrm{O}_{3}$ were lower in those subjects with the greatest initial decrements in lung function suggesting that this mechanism may have been impaired.

These data support the view that the lung function response is predictive of both the development of an active inflammation (if not of the absolute increase in neutrophil numbers), of the subsequent loss, or activation of macrophages, and the significant decrease in RTLF ascorbate concentrations. Although the low ascorbate concentrations after exposure to $\mathrm{O}_{3}$ may reflect a response to airway inflammation rather than a direct consequence of altered lung function, the relation between initial decrements and neutrophil activation, on a per cell basis is notable. It is possible that the reporting of neutrophils as a \% of total cells and then using this as a correlate for lung function responses may have led to the detection of artifactual associations in previous studies. Also, it is clearly more meaningful to consider whether neutrophils (resident or marginating into the lung) are activated as a consequence of exposure to $\mathrm{O}_{3}$, rather than simply considering the change in cell number after challenge.

The current study showed a profound effect of $\mathrm{O}_{3}$ on the redox state of fluid lining the respiratory tract 6 hours after the end of exposure. In the light of our earlier findings at 1.5 hours after exposure we think that this reflects a consequence of the developing airway inflammation. Indeed, we found this response to be contemporaneous with increased neutrophil numbers and myeloperoxidase concentrations after $\mathrm{O}_{3}$. We also found a loss of macrophages, which seemed to be related to the extent of airway inflammation. Given the limitation of using a single bronchoscopy sampling point to 
follow responses in the fluid lining the respiratory tract it was difficult to show direct cause and effect between these processes. Evidence of a small decrease in plasma ascorbate concentrations over the period after exposure was also found, possibly reflecting an adaptive response to the oxidative stress within the lung. Furthermore, it seemed that the magnitude of individual initial pulmonary decrements to $\mathrm{O}_{3}$ was predictive of the antioxidant and inflammatory responses in the fluid lining the respiratory tract found at 6 hours after exposure. Further work will be necessary to dissect out the precise relation between inflammation and alterations in the fluid lining the respiratory tract induced by $\mathrm{O}_{3}$ and antioxidants. Also, it will be interesting to examine whether ascorbate supplementation, targeted to the fluid lining the respiratory tract, would represent an effective strategy in limiting inflammatory injury induced by $\mathrm{O}_{3}$.

We thank John A Sommerville, Jackie Madden, and Nick J Withers for their technical assistance.

1 Bascom R, Bromberg PA, Costa DA, et al. Health effects of outdoor air pollution. Am $\mathcal{f}$ Respir Crit Care Med outdoor air poll.

2 Department of Health Advisory Group on the Medical Aspects of Air Pollution. First report: ozone. London: Aspects of Air Pollution. First report: ozone. Lo

3 Pryor WA. Mechanisms of radical formation from reactions Pryor WA. Mechanisms of radical formation from reactions
of ozone with target molecules in the lung. Free Radic Biol of ozone with target molecules in the lung. Free Radic Biol
Med 1994;17:451-65.

4 Pryor WA. Ozone in all its reactive splendor. $f \mathrm{Lab}$ Clin $\mathrm{Med}$ 1993;122:483-6.

5 Postlethwait EM, Langford SD, Bidani A. Determinants of inhaled ozone absorption in isolated rat lungs. Toxicol Appl Pharmacol 1994;125:77-89.

6 Pryor WA, Squadrito GL, Friedman M. The cascade mechanism to explain ozone toxicity: the role of lipid ozonation products. Free Rad Biol Med 1995;19:935-41.

7 Langford SD, Bidani A, Postlethwait EM. Ozone-reactive absorption by pulmonary epithelial lining fluid constituents. Toxicol Appl Pharmacol 1995;132:122-30.

8 Kelly FJ, Mudway I, Krishna MT, et al. The free radical basis of air pollution: focus on ozone. Respir Med 1995;89: basis of

9 Schelegle ES, Siefkin AD, McDonald RJ. Time course of Schelegle ES, Siefkin AD, McDonald RJ. Time course of
ozone-induced neutrophilia in normal humans. Am Rev ozone-induced neutrophilia
Respir Dis 1991;143:1353-8.

10 Barnes PJ. Reactive oxygen species and airway inflammation. Free Radic Biol Med 1990;9:235-43.

11 Mudway I, Kelly FJ, Khrishna T, et al. Upper airways loss of uric acid during exposure to ozone [abstract]. Eur F Respir Dis 1996;9:415s.

12 Blomberg A, Mudway I, Frew A, et al. Dose-dependent antioxidant and cellular responses in the airways of human subjects exposed to ozone [abstract]. Eur Respir $\mathscr{F}$ 1996;9:147s

13 Baker MA, Cerniglia GJ, Zaman A. Microtiter plate assay for the measurement of glutathione and glutathione disulfide in large numbers of biological samples. Anal Biochem 1990;190:360-5.

14 Iriyama $\mathrm{K}$, Yoshiura $\mathrm{M}$, Iwamoto $\mathrm{T}$, et al. Simultaneous determination of uric and ascorbic acids in human serum by reversed-phase high-performance liquid chromatogra- phy with electrochemical detection. Anal Biochem 1984; $141: 238-43$

15 Bieri JG, Tolliver TJ, Catignani GL. Simultaneous determination of alpha-tocopherol and retinol in plasma or red cells by high pressure liquid chromatography. Am $\mathcal{F}$ Clin Nutr 1979;32:2143-9.

16 Smith PK, Krohn RI, Hermanson GT, et al. Measurement of protein using bicinchoninic acid. Anal Biochem 1985; 150:76-85.

17 Waynor DD, Barton GW, Ingold KU, et al. The relative contributions of vitamin $\mathrm{E}$, urate, ascorbate, and proteins to the total peroxyl radical trapping antioxidant activity of human blood plasma. Biochem Biophys Acta 1987;924:40819.

18 Chirico S. High-performance liquid chromatography-based hiobarbituric acid tests. Methods Enzymol 1994;233:314-

19 Kelly FJ, Blomberg A, Frew AJ, et al. Antioxidant kinetics in lung lining fluid following exposure of human to nitrogen dioxide Am F Respir Crit Care Med 1996;154:1700-5.

20 Reznick AZ, Packer L. Oxidative damage to proteins: spectrophotometric method for carbonyl assay. Methods Enzymol 1994;233:357-63.

21 Slade R, Crissman K, Norwood J, et al. Comparison of antioxidant substances in bronchoalveolar lavage cells and fluid from humans, guinea pigs, and rats. Exp Lung Res 1993;19: 469-84.

22 Mudway IS, Housley D, Eccles R, et al. Differential depletion of human respiratory tract antioxidants in response to ozone challenge. Free Radic Res 1996;25:499513.

23 Giamalva D, Church D, Pryor W. A comparison of the rates of ozonation of biological antioxidants and linoleate esters. Biochem Biophys Res Commun 1985;133:773-9.

24 Mudway I, Kelly FJ. Consumption kinetics of water soluble antioxidants in lung lining fluid by ozone [abstract]. F Free Radic Biol Med 1994;9:M/O15.

25 Frei B. Ascorbic acid protects lipids in human plasma and low density lipoprotein against oxidative damage. Am $\mathcal{F}$ Clin Nutr 1991;54:1113S-8S.

26 Stocker R, Frei B. Endogenous antioxidant defences in human blood plasma. In: Sies $\mathrm{H}$, ed. Oxidative stress: oxidants and antioxidants. San Diego: Academic Press, 1991;213-43.

27 Frei B, Forte TM, Ames BN, et al. Gas phase oxidants of cigarette smoke induce lipid peroxidation and change in lipoprotein properties in human blood plasma. Protective effects of ascorbic acid. Biochem f 1994;277:133-8.

28 Cross CE, Forte T, Stocker R, et al. Oxidative stress and abnormal cholesterol metabolism in patients with adult respiratory distress syndrome. F Lab Clin Med 1990;115: 396-404.

29 Chow CK, Thacker RR, Changchit C, et al. Lower levels of vitamin $\mathrm{C}$ and carotenes in plasma of cigarette smokers. $\mathcal{F}$ Am Coll Nutr 1986;5:305-12.

30 Slade R, Highfill JW, Hatch GE. Effects of depletion of ascorbic acid or nonprotein sulfhydryls on the acute inhalation toxicity of nitrogen dioxide, ozone and phosgene. Inhalation Toxicology 1989;1:261-71.

31 Wiester MJ, Tepper JS, Winsett DW, et al. Adaptation to ozone in rats and its association with ascorbic acid in the lung. Fundam Appl Toxicol 1996;31:56-64.

32 Aris RM, Christian D, Hearne PQ, et al. Ozone-induced airway inflammation in human subjects as determined by airway lavage and biopsy. Am Rev Respir Dis 1993;148:1363-

33 Koren HS, Hatch GE, Graham DE. Nasal lavage as a tool in assessing acute inflammation in response to inhaled pollutants. Toxicology 1990;60:15-25.

34 Vera JC, Rivas CI, Fischbarg J, et al. Mammalian facilitated hexose transporters mediate the transport of dehydroascorbic acid. Nature 1993;364:79-82.

35 Frampton MW, Morrow PE, Torres A, et al. Effects of ozone on normal and potentially sensitive human subjects. Part II: Airway inflammation and responsiveness to ozone in nonsmokers and smokers. Health Effects Institute Research Report 1997;78:39-72. 